\title{
STRATEGI MENINGKATKAN MUTU CALON GURU AGAMA ISLAM
}

\author{
Muhammad Munadi \\ Siti Choiriyah \\ Noor Alwiyah \\ IAIN Surakarta Jl. Pandawa Pucangan Kartasura Sukoharjo \\ Email: muhammadmunadi@yahoo.com
}

\begin{abstract}
ABSTRAK
Penelitian ini bertujuan mendeskripsikan strategi meningkatkan mutu calon Guru (agama) Pendidikan Agama Islam di beberapa perguruan tinggi Islam swasta. Metode penelitian yang dipakai adalah metode penelitian kualitatif. Alat pengumpul data yang dipakai adalah observasi, wawancara dan dokumentasi. Analisis data menggunakan analisis interaktif. Hasil penelitian menunjukkan bahwa strategi peningkatan mutu calon guru Pendidikan Agama Islam dilakukan dengan cara 1) menguatkan keilmuan ke-Islam-an melalui mentoring-kokurikuler, 2) memecah mata kuliah metodologi pembelajaran agama Islam menjadi lebih spesifik, seperti menjadi fiqh, akhlak dan tauhid, 3) mengaplikasikan pembelajaran komputer berbasis internet untuk meng ир-date materimateri PAI secara lebih terbuka, 4) sedemikian rupa melibatkan pondok pesantren, 5) membentuk "think like a teacher" dan "act like a teacher" secara bersama melalui sinergi dan integrasi kegiatan intrakurikuler, kokurikuler dan ekstrakurikuler.
\end{abstract}

Kata Kunci: Strategi, Mutu, Calon guru, Pendidikan Agama Islam

\section{ABSTRACT}

The aim of the paper is to describe strategy improve the quality of Islamic religious education teacher candidates at some private colleges. The method of the paper was qualitative. Instruments of data collection are observation, interview and document analysis. Analysis used interactive. The result are 1) strengthen islamic science throught mentoring cocurriculer, 2) splitting of Islamic religion learning methodology be a fiqh, akhlaq, and tawheed; 3) applicating of the computer instruction based on internet to up-date the materials of Islamic Religion, 4) involving the boarding school, 5) built think like a teacher and act like a teacher all together more integrated with intra, co, and extracurricular.

Keywords: Strategy, Quality, Teacher candidate, Instruction of Islamic Religion 


\section{PENDAHULUAN}

Ketika dilihat dari kualitas standar nasional, umumnya guru Pendidikan Agama Islam (PAI) masih belum memenuhi standar kualifikasi yang dipersyaratkan. PP No. 19 Tahun 2006 tentang Standar Nasional Pendidikan pasal 29 menyatakan bahwa setiap pendidik, pada semua jenjang, minimal harus lulus strata 1 atau diploma IV (S-1/D-IV). Ternyata, standar lulusan tenaga pendidik ini belum terpenuhi sepenuhnya. Berikut adalah tabel keadaan guru Pendidikan Agama Islam berdasarkan lulusannya.

Tabel 1. Keadaan Guru Pendidikan Agama Islam Tahun 2007/2009

\begin{tabular}{|c|c|c|}
\hline Lulusan & Jumlah & Prosentasi \\
\hline$<$ S1 & 86.577 & 51,44 \\
\hline S S2 & 80.086 & 47,61 \\
\hline$>$ S2 & 1.539 & 0,92 \\
\hline Jumlah & $\mathbf{1 6 8 . 1 8 4}$ & \\
\hline \multicolumn{2}{|c|}{ Direktorat Jenderal Pendidikan Islam 2009 }
\end{tabular}

Tabel di atas menunjukkan bahwa guru PAI yang masih memiliki kualifaksi lulusan di bawah strata 1 berjumlah 86.577 atau sekitar 51,44\%. Tingginya prosentase guru PAI yang lulusannya masih di bawah S-1 ini menuntut Departemen Agama (Kementerian Agama) membuat kebijakan strategis dalam bidang peningkatan mutu, relevansi dan daya saing, dengan cara melakukan rekruitmen pendidik dan tenaga kependidikan hanya berdasarkan kualifikasi dan kompetensi minimal lulusan S-1(Imam Tholkhah, 2008).

Perekrutan pendidik dari lulusan strata 1 pun tidak secara otomatis mendogkrak mutu guru PAI. Walaupun guru sudah dididik di tingkat sarjana, tidak secara otomatis guru memiliki kompentensi sesuai dengan tuntutan standar nasional. Kualitas calon guru Pendidikan Agama Islam (mahasiswa jurusan/program studi PAI) yang di persiapkan di Perguruan Tinggi Agama Islam harus terus ditingkatkan kualitas, baik akademik, pedagogik, profesional maupun kepribadiannya.

Jumlah mahasiswa yang terdaptar sebagai calon guru PAI di Perguruan Tinggi Agama Islam (PTAI) baik swasta maupun negeri termasuk yang paling banyak dibandingkan dengan jumlah mahasiswa jurusan atau program studi lainnya. Berarti, di satu sisi minat lulusan sekolah menengah (SMA/SMK/MA) untuk mendaftar sebagai calon guru Agama Islam masih tinggi. Namun di sisi lain, cepat atau lambat dapat mengakibatkan terjadinya surplus calon guru Pendidikan Agama Islam. Perguruan Tinggi Agama Islam (PTAI) yang berada di bawah Kementerian/Departemen Agama (Depag) RI, yang sampai sekarang jumlahnya mencapai 577 buah (53 Negeri dan 524 Swasta) itu, sebagian besar atau sekitar $90 \%$ membuka/menyelenggarakan Jurusan/Program Studi PAI. Oleh karena itu sebagian besar lulusan PTAI berasal dari Jurusan/Prodi PAI. Kebutuhan lembaga pendidikan di tanah air baik sekolah, madrasah maupun pesantren yang dapat menyerap lulusan PAI cenderung tidak menuntut lulusan 
PAI sebanyak itu. Mungkin karena Jurusan/ Program Studi PAI dianggap oleh masyarakat masih memiliki masa depan yang cerah dibanding dengan jurusanjurusan lain di PTAI. Keadaan semacam ini yang menjadikan kontrol terhadap kualitas lulusan PAI terabaikan.

Dengan populasi yang besar, mutu lulusan mahasiswa Jurusan/Program Studi PAI yang ada di seluruh PTAI di Indonesia tidak secara otomatis dapat dipertanggungjawabkan. Sekalipun secara formal lulusannya dipersiapkan untuk menjadi guru PAI di Sekolah dan/atau menjadi guru bidang studi Al-Qur'an alHadits, Aqidah Akhlak, Fiqih, dan Sejarah Peradaban Islam di Madrasah, namun belum sepenuhnya dapat memenuhi tuntutan Sekolah dan Madrasah. Secara praktis, tuntutan calon guru Agama Islam di sekolah dan di madrasah pun berbeda. Pihak yang memerlukan guru PAI secara umum adalah sekolah-sekolah umum yang berada di bawah binaan Kementerian Pendidikan Nasional dan Kebudayaan. Pihak yang memerlukan guru bidang studi Agama Islam (PAI) secara spesifik, seperti guru Bidang Studi Al-Qur'an Hadits, Aqidah Akhlak, dan Fiqih adalah madrasah-madrasah yang berada di bawah binaan Kementerian Agama. Dalam rangka meningkatkan mutu lulusan calon guru Agama Islam (PAI), agar sesuai dengan kebutuhan pemakainya, PTAI memerlukan perlakuan dan strategi khusus yang berbeda-beda.

Tulisan ini bertujuan mengkaji perbedaan strategi dalam meningkatkan mutu calon Guru Agama Islam/Pendidikan Agama Islam. Subjek yang diteliti adalah Universitas Muhammadiyah Surakarta (UMS) dan Universitas Nahdatul Ulama (UNU) Surakarta. UMS merepresentasikan kebutuhan guru Pendidikan Agama Islam di sekolah umum sedangkan UNU merepresentasikan kebutuhan guru-guru bidang studi Agama Islam di madrasah. Perbedaan strategi peningkatan mutu calon Guru Agama Islam dan/atau Pendidikan Agama Islam di antara keduanya, dapat dijadikan sebagai alternatif model konsep strategi peningkatan mutu calon Guru Agama Islam dan/atau Pendidikan Agama Islam oleh Perguruan Tinggi Agama Islam (PTAI) lain di Indonesia.

Metode Penelitian yang digunakan adalah metode penelitian kualitiatif. Data dikumpulkan melalui observasi, wawancara dan analisis dokumentasi. Data dianalisis berdasarkan teori-teori pendidikan Islam.

\section{PEMBAHASAN}

Rekruitmen mahasiswa Program Studi Pendidikan Agama Islam (PAI) di Fakultas Agama Islam Universitas Nahdatul Ulama (UNU) dan di Universitas Muhamammadiyah Surakarta (UMS) sama-sama dilakukan melalui dua jalur, yaitu jalur tes dan non tes. Jalur tes dilakukan dalam rangka menyaring kemampuan calon mahasiswa dalam kemampuan dalam bidang akademik, misalnya mengukur potensi dasar membaca dan berhitung, kemampuan menalar, dan kemampuan dalam bidang ilmu agama Islam. Jalur non tes dilakukan dalam rangka menyaring kemampuan calon mahasiswa dalam bidang pendukund akademik, misalnya minat dan motivasi memilih Program Studi PAI. 
Penjaminan mutu Program Studi PAI di UNU dan UMS dilakukan melalui Penjaminan Mutu Kurikulum PAI (PMKPAI-UNU). Penjaminan mutu kurikulum PAI pada kedua lembaga ini dilakukan dengan penguatan Ilmu Dasar ke-Islaman. Penguatan Ilmu Dasar ke-Islaman pada dua lembaga ini agak berbeda. Berikut adalah tabel perbandingan Penguatan Ilmu Dasar Ke-Islaman yang diselenggarakan oleh UNU dan UMS.

Tabel 2. Penguatan Ilmu Dasar Ke-Islaman

\begin{tabular}{|c|c|}
\hline Perguruan Tinggi & Semester $\mathbf{1}$ dan $\mathbf{2}$ \\
\hline UMS & Mentoring kokurikuler \\
\hline UNU & Ekstrakurikuler \\
\hline
\end{tabular}

Tabel di atas menunjukkan bahwa penguatan Ilmu Dasar Ke-Islaman yang diselenggarakan baik oleh UNU maupun UMS diberikan pada mahasiswa semester 1 dan 2. Dalam hal bentuk pelaksanaannya, kedua lembaga menempuh cara yang berbeda. UMS melaksanakan penguatan Ilmu Dasar Ke-Islaman dalam bentuk mentoring kokurikuler. Sejak semester III, mahasiswa dilatih untuk menjadi mentor selama 2 semester sekaligus menjadi pengelola kegiatan mentoringnya. Mahasiswa tersebut dilatih menjadi calon guru, yakni dengan belajar mengelola kegiatan pembelajaran. Setiap mahasiswa yang telah menjadi mentor diwajibkan mengelola/menangani dan membelajarkan 8-10 mahasiswa selama 2 semester. Mentor bertanggungjawab penuh atas kehadiran para peserta mentoring (mentee). Para mentor memotivasi mentee untuk bisa membaca dan menulis al-Qur'an, menghafal surat-surat pendek dan mampu melaksanakan tertib ibadah keseharian dengan baik dan benar. Para mentor harus mempertanggungjawabkan hasil mentoringnya kepada pengelola mentor dan Jurusan PAI di UMS.

Kegiatan mentoring menjadikan para peserta mentoring (para mentee) cepat menguasai materi dasar keilmuan keislaman termasuk terampil dalam praktik tilawah dan ibadah. Dalam kegiatan mentoring, mahasiswa senior (para mentor) dilatih mengembangkan diri menjadi guru secara mikro, karena mereka diwajibkan mengajari mahasiswa dalam kelompok kecil ketika kegiatan mentoring berlangsung. Secara makro, mereka juga belajar mengelola lembaga pendidikan sejak dini karena sedemikian rupa, lembaga mentoring dibuat "mirip dengan sekolah". Intinya, mentoring kokurikuler memberikan kesempatan kepada seluruh mahasiswa, untuk Learning to Be dan Learning to Live Together. Mahasiswa senior (mentor) betul-betul menghayati menjadi guru dengan cara belajar mengajari mahasiswa juniornya (mentee). Seluruh mahasiswa (mentor dan mentee) menghayati kegiatan mentoring dalam suasana silaturrahim, kebersamaan, dan kekeluargaan. Secara tidak langsung, mahasiswa mendapatkan bekal soft-skill. Mahasiswa yang terlibat dalam kegiatan mentoring kokurikuler minimal menyadari bahwa dirinya memerlukan semangat untuk senantiasa mengembangkan diri. Bagaimanapun juga dalam pelaksanaan kegiatan mentoring 
kokurikuler, sedikit atau banyak mereka menghadapi kendala. Dengan terdeteksinya kendala, mereka belajar memcahkan kendala itu secara terkendali. Pengendalian emosi adalah aspek yang cukup penting dalam mengembangkan soft skills seseorang. Sebaliknya, soft skills juga sangat membantu dalam mengembangkan seluruh potensi pedagogik seseorang bahkan kelak setelah mahasiswa lulus yakni pada saat ia bekerja. Mai (www.voced.edu.au 2010) menyatakan 'soft skills' as those skills which can support study in any discipline and also skills that have the potential to be transferred to a range of contexts, education and workplace.

Memiliki soft skills yang baik menjadikan seseorang bisa luwes dalam bergaul dan bersikap, baik terhadap sesama maupun terhadap makhluk lain serta lingkungan sekitar. Seseorang yang memiliki soft skills yang baik akan senantiasa bermanfaat di manapun ia berada. Ia tidak akan menjadi beban bagi orang lain. Soft skills dapat melengkapi hard skills. Sifatnya yang melengkapi, menjadikan soft skills memiliki dua ruang lingkup, yaitu lingkup atribut personal dan kemampuan interpersonal. Lingkup atrubut personal mencakup optimisme, common sense, tanggungjawab, cita rasa humor, integritas, pengelolaan waktu, dan motivasi. Lingkup kemampuan interpersonal yaitu empati, kemampuan komunikasi, berpikir dan bersikap (positif) yang baik, kemampuan sosial, dan kemampuan mengajar. Dengan keikutsertaan mahasiswa dalam kegiatan mentoring kokurikuler setidaknya menjadikan mahasiswa lebih siap untuk menghadapi siswa dan teman sejawat serta (stakeholder) kelak ketika mereka bekerja di dunia pendidikan yang sesungguhnya.

UNU memilih penguatan Ilmu Dasar Ke-Islaman dalam bentuk ekstrakurikuler. Mereka menitipkan seluruh mahasiswa semester 1 dan 2 ke beberapa pondok pesantren di sekitar kampus UNU. Kultur pesantren dianggap oleh UNU dapat lebih membekali mahasiswa dalam menguasai ilmu-ilmu Agama Islam.

UMS dan UNU juga melakukan penguatan konten PAI secara kurikuler. Penguatan konten PAI secara kurikuler dapat dilihat pada tabel berikut ini:

Tabel 3. Penguatan Konten PAI

\begin{tabular}{|c|c|}
\hline Perguruan Tinggi & Konten PAI \\
\hline UMS & $\begin{array}{l}\text { Aqidah } \\
\text { Akhlak } \\
\text { Ushul Fiqh } \\
\text { Ulumul Qur'an } \\
\text { Ulmul Hadis } \\
\text { Fiqh Ibadah } \\
\text { Fiqh Kontemporer } \\
\text { Hadis Tarbawi }\end{array}$ \\
\hline & $\begin{array}{l}\text { Ilmu Mantiq } \\
\text { Ilmu Kalam } \\
\text { Ilmu Tasawuf } \\
\text { Ushul figh }\end{array}$ \\
\hline
\end{tabular}




\begin{tabular}{|l|l|}
\hline \multicolumn{1}{|c|}{ Perguruan Tinggi } & \multicolumn{1}{c|}{ Konten PAI } \\
\hline UNU & Ulumul Qur'an \\
& Ulmul Hadis \\
& Fiqh \\
& Tafsir \\
& Hadis \\
& Materi PAI (Aqidah Akhlak) \\
& Materi PAI (Fiqh) \\
& Materi PAI (Tafsir) \\
& Masailul Fiqh al Haditsah 1 dan 2 \\
& Perbandingan Madzhab 1 dan 2 \\
\hline
\end{tabular}

Tabel di atas menunjukkan bahwa kedua lembaga Perguruan Tinggi Agama Islam ini, sama-sama telah menguatkan penguasaan konten mahasiswa terhadap PAI dengan cara menambah materi/bidang studi/mata kuliah keagamaan Islam. Penekanan penguatan konten PAI pada kedua lembaga ini agak berbeda. UMS menguatkan konten PAI-nya dengan cara menambah lebih banyak materi ilmu-ilmu keislaman sebagai produk, sejak zaman klasik hingga zaman kontemporer. Aktualisasi produk keilmuan Islam menjadi focus penguatan konten PAI di UMS. UNU lebih fokus menguatkan konten PAI-nya pada materi fiqih dan tidak hanya sebagai produk namun juga sebagai proses. Mahasiswa diberikan beragam perangkat keilmuan untuk menghasilkan produk fiqih. Ada tujuh materi kajian Fiqih dalam kurikulum PAI di UNU. UNU memisahkan materi PAI ke dalam 3 mata kuliah yaitu Materi PAI (Aqidah Akhlak), Materi PAI (Fiqih), dan Materi PAI (Tafsir).

Penguatan konten atau bidang studi keislaman kemudian diseimbangkan dengan penguatan kompetensi pedagogik mahasiswa. Kompetensi pedagogik ini penting sebab mahasiswa secara formal "diformat" untuk menjadi guru atau tenaga pengajar mata pelajaran (Pendidikan) Agama Islam. Dua lembaga PTAI ini melakukan langkah yang berbeda dalam membekali mahasiswanya dengan kompetensi pedagogik. Berikut adalah tabel perbandingan penguatan kompetensi pedagogik antara UNU dengan UMS.

Tabel 4. Penguatan Kompetensi Pedagogik Program Studi PAI di UNU dan UMS

\begin{tabular}{|c|l|}
\hline Perguruan Tinggi & \multicolumn{1}{c|}{ Kompetensi Pembelajaran PAI } \\
\hline & Pendidikan Figh \\
Pendidikan al- Qur'an \\
Pendidikan Hadis \\
Pendidikan SKI \\
UMS & Pendidikan Aqidah \\
& Pendidikan Akhlak \\
& Perencanaan Sistem PAI \\
& Pengembangan Evaluasi \\
& Pengembangan Kurikulum PAI \\
\hline
\end{tabular}




\begin{tabular}{|c|l|}
\hline Perguruan Tinggi & \multicolumn{1}{|c|}{ Kompetensi Pembelajaran PAI } \\
\hline & Penyusunan Buku Ajar \\
& Komputer Studi Islam \\
& Micro Teaching \\
& PPL \\
\hline & Metodologi PAI 1 dan 2 \\
& Perencanaan Sistem PAI \\
& Pengembangan Evaluasi \\
& Pengembangan Kurikulum PAI \\
& Media Pembelajaran PAI \\
& Micro Teaching \\
& PPL \\
\hline
\end{tabular}

Tabel di atas menunjukkan bahwa strategi yang dipakai oleh UMS untuk membekali kompetensi pedagogik mahasiswa Program Studi PAI (Calon guru Agama Islam) agar siap mengajar semua bidang studi yang dibutuhkan di madrasah dengan cara menambahkan mata kuliah Komputer Studi Islam. Mata kuliah Komputer Studi Islam merupakan mata kuliah berbasis teknologi informasi yang dikolaborasikan dengan sejumlah mata kuliah kependidikan/pedagogik seperti perencanaan, pengembangan dan teknik evaluasi pembelajaran PAI. Dengan terlebih dahulu dilakukan penyesuaian terhadap jenis-jenis mata pelajaran di madrasah binaan Kementerian Agama, mata kuliah Komputer Studi Islam dirancang untuk mengarahkan mahasiswa agar bisa memanfaatkan berbagai produk Information Technology (IT) untuk mengembangkan teknik-teknik pembelajaran. Pemanfaatan produk-produk teknologi informasi bisa berupa pemanfaatan soft ware, electronic book, dan jaringan internet untuk pembelajaran PAI. Dengan dibekal mata kuliah Komputer Studi Islam, calon guru PAI bisa meng-up date berbagai informasi dan hasil-hasil penelitian terbaru dalam bidang Pendidikan Agama Islam. Mahasiswa juga dibekali dengan kemampuan teknis penyusunan bahan ajar agama yakni Mata Kuliah Penyusunan Buku Ajar.

Tabel di atas juga menunjukkan bahwa penambahan sejumlah mata kuliah penguatan kompetensi pedagogik/teknis-teknis pembelajaran yang dilakukan oleh UNU dan UMS, secara umum memiliki kesamaan. Salah satu kesamaan tersebut adalah pemberian mata kuliah baku seperti Metodologi PAI, Perencanaan Sistem PAI, Pengembangan Sistem Evaluasi PAI, Pengembangan Kurikulum PAI, Media Pembelajaran PAI, Micro Teaching, dan PPL. Perbedaannya hanya pada jumlah SKS yang harus disajikan dan perincian teknisnya.

Perubahan yang cepat pada dunia kerja, baik dalam bidang pendidikan maupun dalam bidang lainnya, menuntut Perguruan Tinggi Agama Islam harus mempersiapkan dengan sungguh-sungguh calon tenaga pendidik dan tenaga kependidikan yang ia bina. Sebagai calon guru Agama Islam dan calon tenaga kependidikan, seluruh mahasiswa harus dididik dan dilatih agar memiliki 
berbagai kompetensi yang dibutuhkan di dunia kerja. Kompetensi tersebut dijabarkan dalam tiga tingkatan. Ketiga tingkatan tersebut tergambarkan dalam tabel berikut ini.

Tabel 5. Gradasi (Tingkatan) Kompetensi Kunci

\begin{tabular}{|c|c|c|c|c|}
\hline & Kompetensi Kunci & $\begin{array}{c}\text { Tingkat } 1 \text { “Melakukan } \\
\text { Kegiatan" }\end{array}$ & $\begin{array}{l}\text { Tingkat } 2 \\
\text { “Mengelola } \\
\text { Kegiatan" }\end{array}$ & $\begin{array}{c}\text { Tingkat } 3 \\
\text { “Mengevaluasi } \\
\text { dan } \\
\text { Memodifikasi } \\
\text { Proses" }\end{array}$ \\
\hline 1. & $\begin{array}{l}\text { Mengumpulkan, } \\
\text { menganalisis dan } \\
\text { mengorganisir } \\
\text { informasi }\end{array}$ & $\begin{array}{l}\text { Mengakses dan merekam } \\
\text { dari satu sumber }\end{array}$ & $\begin{array}{l}\text { Mengakses, memilih } \\
\text { \& merekam lebih } \\
\text { dari satu sumber }\end{array}$ & $\begin{array}{l}\text { Mengakses, } \\
\text { mengevaluasi } \\
\text { mengorganisir } \\
\text { berbagai sumber }\end{array}$ \\
\hline 2. & $\begin{array}{l}\text { Mengomunikasikan } \\
\text { ide dan informasi }\end{array}$ & $\begin{array}{l}\text { Pengaturan sederhana } \\
\text { yang telah lazim/familier }\end{array}$ & $\begin{array}{l}\text { Berisi hal-hal yang } \\
\text { kompleks }\end{array}$ & $\begin{array}{l}\text { Mengakses, } \\
\text { mengevaluasi dan } \\
\text { mengomunikasi- } \\
\text { kan } \\
\text { nilai/perubahan } \\
\text { dari berbagai } \\
\text { sumber }\end{array}$ \\
\hline & $\begin{array}{l}\text { Merencanakan dan } \\
\text { mengorganisir } \\
\text { kegiatan }\end{array}$ & $\begin{array}{l}\text { Di bawah pengawasan } \\
\text { atau supervisi }\end{array}$ & $\begin{array}{l}\text { Dengan bimbingan/ } \\
\text { panduan }\end{array}$ & $\begin{array}{l}\text { Inisiasi mandiri } \\
\text { dan mengevaluasi } \\
\text { kegiatan kompleks } \\
\text { dengan cara } \\
\text { mandiri } \\
\end{array}$ \\
\hline 4. & $\begin{array}{l}\text { Bekerjasama dengan } \\
\text { orang lain \& } \\
\text { kelompok }\end{array}$ & $\begin{array}{l}\text { Kegiatan-kegiatan yang } \\
\text { sudah dipahami/aktivitas } \\
\text { rutin }\end{array}$ & $\begin{array}{l}\text { Membantu } \\
\text { merumuskan tujuan }\end{array}$ & $\begin{array}{l}\text { Berkolaborasi } \\
\text { dalam } \\
\text { menyelesaikan } \\
\text { kegiatan-kegiatan } \\
\text { kompleks }\end{array}$ \\
\hline & $\begin{array}{l}\text { Meggunakan ide-ide } \\
\text { dan teknik } \\
\text { matematika }\end{array}$ & $\begin{array}{l}\text { Tugas-tugas yang } \\
\text { sederhana dan telah } \\
\text { ditetapkan }\end{array}$ & $\begin{array}{l}\text { Memilih ide dan } \\
\text { teknik yang tepat } \\
\text { untuk tugas yang } \\
\text { kompleks }\end{array}$ & $\begin{array}{l}\text { Berkolaborasi } \\
\text { dalam } \\
\text { menyelesaikan } \\
\text { tugas yang } \\
\text { kompleks }\end{array}$ \\
\hline & $\begin{array}{l}\text { Memecahkan } \\
\text { masalah }\end{array}$ & $\begin{array}{l}\text { Rutin di bawah } \\
\text { pengawasan }\end{array}$ & $\begin{array}{l}\text { Rutin dan dilakukan } \\
\text { sendiri berdasarkan } \\
\text { pada panduan }\end{array}$ & $\begin{array}{l}\text { Problem/ masalah } \\
\text { yang kompleks } \\
\text { dengan } \\
\text { menggunakan } \\
\text { pendekatan yang } \\
\text { sistimatis, serta } \\
\text { mampu mengatasi } \\
\text { problemnya }\end{array}$ \\
\hline & $\begin{array}{l}\text { Menggunakan } \\
\text { teknologi }\end{array}$ & $\begin{array}{l}\text { Membuat kembali/ } \\
\text { memproduksi/ } \\
\text { memberikan jasa/yang } \\
\text { berulang pada tingkat } \\
\text { dasar }\end{array}$ & $\begin{array}{l}\text { Mengontruksi, } \\
\text { mengorganisir atau } \\
\text { menjalankan produk } \\
\text { atau jasa }\end{array}$ & $\begin{array}{l}\text { Merancang, } \\
\text { menggabungkan } \\
\text { atau memodifikasi } \\
\text { produk atau jasa }\end{array}$ \\
\hline
\end{tabular}

(Subiyakto Tjakrawerdaya, tt)

Tabel di atas menunjukkan bahwa kompetensi kunci memiliki tiga tingkatan yaitu melakukan, mengelola, dan mengevaluasi serta memodifikasi 
proses. Dengan demikian seseorang yang memiliki soft skills yang tinggi adalah orang yang memiliki tiga tingkat sekaligus. Berikut tabel tingkatan kompetensi beserta masing-masing elemennya.

Tabel 6. Elements of Soft Skills

\begin{tabular}{|c|c|c|c|}
\hline No. & Soft Skills & $\begin{array}{c}\text { Must Have Elements (Sub- } \\
\text { Skills) }\end{array}$ & $\begin{array}{c}\text { Good To Have Elements } \\
\text { (Sub-Skills) }\end{array}$ \\
\hline 1. & Communicative Skills & $\begin{array}{l}\text { Ability to deliver idea clearly, } \\
\text { effectively and with confidence either } \\
\text { orally or in writing } \\
\text { Ability to practice active listening } \\
\text { skill and respond. } \\
\text { Ability to present clearly and } \\
\text { confidently to the audience. }\end{array}$ & $\begin{array}{l}\text { Ability to use technology during } \\
\text { presentation. } \\
\text { Ability to discuss and arrive at a } \\
\text { consensus. } \\
\text { Ability to communicate with } \\
\text { individual from a different } \\
\text { cultural background. } \\
\text { Ability to expand one?s own } \\
\text { communicative skill. } \\
\text { Ability to use non-oral skills. }\end{array}$ \\
\hline 2. & $\begin{array}{l}\text { Critical Thinking and } \\
\text { Problem Solving } \\
\text { Skills }\end{array}$ & $\begin{array}{l}\text { Ability to identify and analyze } \\
\text { problems in difficult situation and } \\
\text { make justifiable evaluation. } \\
\text { Ability to expand and improve } \\
\text { thinking skills such as explanation, } \\
\text { analysis and evaluate discussion. } \\
\text { Ability to find ideas and look. for } \\
\text { alternative solutions. }\end{array}$ & $\begin{array}{l}\text { Ability to think beyond.. } \\
\text { Ability to make conclusion } \\
\text { based on valid proof. } \\
\text { Ability to withstand and give } \\
\text { full responsibility. } \\
\text { Ability to understand and } \\
\text { accommodate oneself to the varied } \\
\text { working environment. }\end{array}$ \\
\hline 3. & Team Work & $\begin{array}{l}\text { Ability to build a good rapport, } \\
\text { interact and work effectively with } \\
\text { others. } \\
\text { Ability to understand and play the } \\
\text { role of a leader and follower } \\
\text { alternatively. } \\
\text { Ability to recognize and respect } \\
\text { other?s attitude, behavior and } \\
\text { beliefs. }\end{array}$ & $\begin{array}{l}\text { Ability to give contribution to } \\
\text { the planning and coordinate } \\
\text { group work. } \\
\text { Responsible towards group } \\
\text { decision. }\end{array}$ \\
\hline 4. & $\begin{array}{l}\text { Life-Long Learning } \\
\text { \& Information } \\
\text { Management Skill }\end{array}$ & $\begin{array}{l}\text { Ability to find and manage relevant } \\
\text { information from various sources. } \\
\text { Ability to receive new ideas } \\
\text { performs autonomy learning. }\end{array}$ & $\begin{array}{l}\text { Ability to develop an inquiry } \\
\text { mind and seek. knowledge. }\end{array}$ \\
\hline 5. & Entrepreneurship skill & Ability to identify job opportunities. & $\begin{array}{l}\text { Ability to propose business } \\
\text { opportunity. } \\
\text { Ability to build, explore and } \\
\text { seek. business opportunities and } \\
\text { job. } \\
\text { Ability to be self-employed. }\end{array}$ \\
\hline 6. & $\begin{array}{l}\text { Ethics, Moral \& } \\
\text { Professional }\end{array}$ & $\begin{array}{l}\text { Ability to understand the economy } \\
\text { crisis, environment and social } \\
\text { cultural aspects professionally. } \\
\text { Ability to analyze make problem } \\
\text { solving decisions related to ethics. }\end{array}$ & $\begin{array}{l}\text { Ability to practice etbical } \\
\text { attitudes besides having the } \\
\text { responsibility towards society. }\end{array}$ \\
\hline
\end{tabular}




\begin{tabular}{|c|c|c|c|}
\hline No. & Soft Skills & $\begin{array}{c}\text { Must Have Elements (Sub- } \\
\text { Skills) }\end{array}$ & $\begin{array}{c}\text { Good To Have Elements } \\
\text { (Sub-Skills) }\end{array}$ \\
\hline 7. & Leadership skill & $\begin{array}{l}\text { Knowledge of the basic theories of } \\
\text { leadership. } \\
\text { Ability to lead a project. }\end{array}$ & $\begin{array}{l}\text { Ability to understand and take } \\
\text { turns as a leader and follower } \\
\text { alternatively. } \\
\text { Ability to supervise members of } \\
\text { a group. }\end{array}$ \\
\hline
\end{tabular}

(Archna Sharma, 2009)

Tabel di atas menekankan bahwa soft skills tertinggi adalah leadership skill. Leadership skill is ability to understand and take turns as a leader and follower alternatively and ability to supervise members of a group. Keahlian kepemimpinan adalah kemampuan untuk memahami dan mengambil pilihan alternatif giliran baik sebagai pemimpin maupun sebagai pengikut dan kemampuan untuk mengawasi anggota kelompok. Dalam konteks mentoring kokurikuler kedua kemampuan ini secara terprogram dijelaskan kepada semua peserta mentoring.

Di samping penguatan keagamaaan dan soft skills di atas, dalam menghadapi globalisasi, mahasiswa juga mendapatkan penguatan bahasa asing. Bahasa asing yang diberikan kepada mahasiswa ada dua, yaitu Bahasa Arab dan Bahasa Inggris. Dengan adanya perintisan sekolah bertaraf internasional baik yang berada di bawah Kementerian Pendidikan dan Kebudayaan maupun di bawah Kementerian Agama disikapi oleh PTAI dengan melakukan penguatan bahasa asing kepada mahasiswa PAI.

Deskripsi dan analisis terhadap mata kuliah bahasa asing di masing-masing lembaga baik di UNU maupun di UMS adalah sebagai berikut.

Tabel 7. Penguatan Mata Kuliah Bahasa Asing

\begin{tabular}{|l|l|}
\hline PTAI & \multicolumn{1}{c|}{ Kurikulum Bahasa Arab } \\
\hline UMS & $\begin{array}{l}\text { Bahasa Arab I - IV } \\
\text { Bahasa Arab Asasi I-II }\end{array}$ \\
\hline \multirow{2}{*}{ UNU } & $\begin{array}{l}\text { Bahasa Arab 1-3 } \\
\text { Qowa'id Bahasa Arab } \\
\text { Qiro'atul Kutub 1 - 2 }\end{array}$ \\
\hline
\end{tabular}

Tabel tersebut menunjukkan bahwa penguatan Bahasa Arab yang dilakukan oleh kedua lembaga (UNU dan UMS) relatif sama, yakni menyesuaikan dengan kurikulum nasional yaitu 4 SKS. Hanya dalam aspek pengembangannya, mereka memiliki perbedaan. Muatan Bahasa Arab yang sesuai dengan kurikulum nasional tersebut ditambah Qowa'id Bahasa Arab dan Qiro'atul kutub 1 - 2 ditempuh oleh UNU. Langkah penguatan Bahasa Arab yang dilakukan oleh UMS dengan cara memberikan Mata Kuliah Bahasa Arab sebanyak 6 kali, meliputi Bahasa Arab 1 - 4 dan Bahasa Arab Asasi 1 dan 2. Kemampuan menguasai Bahasa Arab ini menjadi mutlak karena dalam memahami kitab-kitab klasik Islam diperlukan penguasaan Bahasa Arab yang 
kuat. Di samping bahasa arab, mahasiswa diberikan bekal Bahasa Inggris. Sebaran mata kuliah bahasa Inggris adalah sebagai berikut:

Tabel 8. Sebaran Mata Kuliah Bahasa Inggris

\begin{tabular}{|l|l|}
\hline \multicolumn{1}{|c|}{ PTAI } & \multicolumn{1}{c|}{ Kurikulum Bahasa Inggris } \\
\hline UMS & $\begin{array}{l}\text { Bahasa Inggris Dasar 1-3 } \\
\text { Bahasa Inggris 1 }\end{array}$ \\
\hline UNU & Bahasa Inggris 1 - 3 \\
\hline
\end{tabular}

Tabel di atas menunjukkan bahwa penguatan Bahasa Inggris yang dilakukan kedua lembaga relatif sama, yakni mengacu pada kurikulum nasional yaitu 4 SKS. Hal yang membedakan adalah teknis pembelajaran yang dilakukan. Masing-masing lembaga memiliki fokus pembelajaran Bahasa Inggris yang berbeda. Di UNU, penguasaan praktis Bahasa Inggris dalam conversation menjadi prioritas sedangkan di UMS fokus utama pembelajaran Bahasa Inggris-nya adalah writing.

\section{SIMPULAN}

Strategi meningkatkan mutu calon Guru (Agama) Pendidikan Agama Islam yang dilakukan oleh Program Studi PAI Universitas Muhammadiyah Surakarta meliputi: 1) rekruitmen mahasiswa ditempuh melalui tes dan non tes, 2) penguatan Ilmu Dasar Ke-Islaman diberikan dilakukan dengan cara mentoring kokurikuler. Strategi ini dilaksanakan dengan cara mendidik mahasiswa untuk menjadi mentee, mentor dan "pengelola lembaga pendidikan". Kegiatan ini dilakukan di awal semester selama satu tahun, 2) penguatan konten PAI. Strategi ini ditempuh dengan cara memecah Mata Kuliah Pendidikan Agama Islam menjadi dua peruntukan yakni untuk memenuhi kebutuhan menjadi guru Agama Islam di sekolah dan menjadi guru Agama Islam di madrasah. Dalam rangka memenuhi kebutuhan menjadi guru di madrasah, pembelajaran Agama Islam diuraikan menjadi lebih spesifik dan disesuaikan dengan pembagian bidang studi keagamaan Islam di madrasah, seperti Bidang Studi Akidah, Akhlak, Fiqih, Tafsir, Hadis, Tasawuf, Mantiq dan al-Qur'an; 3) penguatan kompetensi pedagogik. Strategi ini ditempuh dengan cara memberikan Mata Kuliah Komputer Studi Islam. Cara ini ditempuh dalam rangka membekali mahasiswa dengan pengetahuan aplikatif Agama Islam berbasis internet agar mahasiswa dapat meng-up-date materi PAI di laman-laman yang direferensikan.

Strategi peningkatan mutu calon Guru (Agama) Pendidikan Agama Islam di Program Studi PAI Universitas Nahdatul Ulama Surakarta (UNU) dilakukan melalui; 1) rekruitmen mahasiswa ditempuh melalui jalur tes dan non tes dengan memprioritaskan calon mahasiswa yang berlatar belakang/berasal dari pondok pesantren, 2) pembinaan dan penguatan materi keislamannya ditempuh dengan cara menitipkan mahasiswa ke sejumlah pondok pesantren yang berada di sekitar 
UNU. Materi PAI kemudian dispesifikasikan sesuai dengan ruang lingkup PAI di madrasah dengan terutama memperkuat Mata Kuliah Fiqh, 3) strategi meningkatkan mutu calon Guru (Agama) Pendidikan Agama Islam dilaksanakan melalui kegiatan intrakuler dan ekstra kurikuler di asrama. Dengan strategi ini, mahasiswa terkondisikan memperdalam Ilmu Agama Islam secara on-going formation sejak semester awal.

\section{DAFTAR PUSTAKA}

Direktur Pendidikan Agama Islam Imam Tholkhah: Guru Depag Belum Penuhi Standar Kualifikasi Yogyakarta, MADINA. http://www.madina-sk.com/ index.php? option $=$ com content\&task $=$ view\&id $=3416 \&$ Itemid $=3$ diunduh 3 Juli 2008

Harmoni, Ati. (tth).Soft Skill, Kegiatan Ektrakurikuler, dan Pilihan Karir.ati@staff.gunadarma.ac.id

Mai, Riam Chau., Simkin, Keith., Cartledge, Damon. Developing Soft Skill in Malaysian, Polytechnics La Trobe University, Melbourne. terdapat dalam http://www.voced.edu.au/docs/confs/ncver/vetconf19/tr19riam.pdf

Miles \& Huberman. 1992. Analisis Data Kualitatif.

Setditjen Pendidikan Islam. (2008). Data Statistik Pendidikan Tahun 2007/2008. Jakarta: Setditjen Pendidikan Islam Depag.

Sharma, Archna. 2009. Importance of Soft skills development in education. http://schoolofeducators.com/2009/02/importance-of-soft-skillsdevelopment-in-education/ diunduh tanggal 02 Tahun 2009.

Tjakrawerdaya, Subiyakto. TT. Pengembangan Sumberdaya Manusia Berbasis Etika dan Budaya Akademik. pps.unnes.ac.id /.../Institut\% 20Nusantara\%20 By\%20Subiakto\%20 Tjakrawerdaja.ppt 